\title{
Potential Target Antigens for a Universal Vaccine in Epithelial Ovarian Cancer
}

\author{
Renee Vermeij,, ${ }^{1}$ Toos Daemen, ${ }^{2}$ Geertruida H. de Bock, ${ }^{3}$ Pauline de Graeff, ${ }^{1}$ Ninke Leffers, ${ }^{1}$ \\ Annechien Lambeck, ${ }^{1}$ Klaske A. ten Hoor, ${ }^{1}$ Harry Hollema, ${ }^{4}$ Ate G. J. van der Zee, ${ }^{1}$ \\ and Hans W. Nijman ${ }^{1}$
}

${ }^{1}$ Department of Gynecological Oncology, University Medical Center Groningen, University of Groningen, P.O. Box 30.001, 9700 RB Groningen, The Netherlands

${ }^{2}$ Department of Medical Microbiology, Molecular Virology Section, University Medical Center Groningen, University of Groningen, P.O. Box 30.001, 9700 RB Groningen, The Netherlands

${ }^{3}$ Department of Epidemiology, University Medical Center Groningen, University of Groningen, P.O. Box 30.001, 9700 RB Groningen, The Netherlands

${ }^{4}$ Department of Pathology and Medical Biology, University Medical Center Groningen, University of Groningen, P.O. Box 30.001, 9700 RB Groningen, The Netherlands

Correspondence should be addressed to Hans W. Nijman, h.w.nijman@og.umcg.nl

Received 7 June 2010; Accepted 16 July 2010

Academic Editor: Wmartin Martin Kast

Copyright (C) 2010 Renee Vermeij et al. This is an open access article distributed under the Creative Commons Attribution License, which permits unrestricted use, distribution, and reproduction in any medium, provided the original work is properly cited.

The prognosis of epithelial ovarian cancer (EOC), the primary cause of death from gynaecological malignancies, has only modestly improved over the last decades. Immunotherapeutic treatment using a cocktail of antigens has been proposed as a "universal" vaccine strategy. We determined the expression of tumor antigens in the context of MHC class I expression in 270 primary tumor samples using tissue microarray. Expression of tumor antigens p53, SP17, survivin, WT1, and NY-ESO-1 was observed in 120 (48.0\%), 173 (68.9\%), 208 (90.0\%), 129 (56.3\%), and 27 (11.0\%) of 270 tumor specimens, respectively. In 93.2\% of EOC, at least one of the investigated tumor antigens was (over)expressed. Expression of MHC class I was observed in 78.1\% of EOC. In 3 out 4 primary tumors, (over)expression of a tumor antigen combined with MHC class I was observed. These results indicate that a multiepitope vaccine, comprising these antigens, could serve as a universal therapeutic vaccine for the vast majority of ovarian cancer patients.

\section{Introduction}

Epithelial ovarian cancer (EOC) is the most common cause of death in gynaecologic malignancies [1]. Most ovarian cancer patients are asymptomatic until disease has metastasized and therefore two-thirds of all patients are diagnosed with advanced stage disease [1,2]. Although the majority of patients with advanced disease achieve complete clinical response rates due to the current therapy of aggressive cytoreductive surgery and platinum-taxanebased chemotherapy, more than $90 \%$ develop tumor recurrence, resulting in five-year survival rates of only $30 \%$ $[3]$.
These records express the need for a new and improved therapy for EOC. The significance of the immune response for the clinical course of EOC has led to attempts to modulate it artificially with (antigen-specific) immunotherapeutic strategies [4]. Presentation of tumor antigens in the context of MHC molecules on tumor cells is critical for the efficacy of targeted immunotherapy [5]. Thus far, approaches at therapeutic vaccination in cancer patients including administration of peptide pulsed dendritic cells, recombinant viral vectors encoding tumor antigen, DNAfusion vaccine and single peptide vaccine have not shown consistent, and high percentages of clinical successes [612]. Most clinical studies on immunotherapy targeted one 
antigen, limiting the use of such vaccines to those patients with (over)expression of that specific tumor antigen. Immunization using a cocktail of antigens has been proposed as a "universal" vaccine strategy. Whereas solid tumors often show heterogeneous protein expression, multiantigen vaccines may have greater therapeutic potential and compensate for tumor antigen-loss variants $[13,14]$. The ability to target multiple antigens, may also improve the immunogenicity of therapeutic vaccines $[13,15]$. Therefore, discovery of multiple tumor antigens in EOC may provide opportunities for multiantigen immunotherapeutic strategies that can induce sufficient clinical responses. Tumor antigens that are inherently immunogenic and oncogenic in ovarian cancer are p53 [16-18], Sperm Protein 17 (SP17) [14, 19, 20], Wilms' tumor gene 1 (WT1) [21-23], survivin [24-26], and NY-ESO-1 [12, 27, 28].

The presence of an $\alpha$ (heavy) chain and $\beta_{2}$-microglobulin is a prerequisite for the formation of a stable MHC class I complex [29]. Such stable MHC class I complexes are required for presentation of the tumor antigenic peptides [30].

No reports have been published describing tissue microarray staining of p53, SP17, survivin, WT1, and NYESO-1 with MHC class I expression in EOC. Further knowledge of the expression of multiple tumor antigens in the context of MHC class I expression is necessary to develop strategies to increase clinical efficacy of multiantigen immunotherapy in EOC.

The aim of the present study was to investigate the expression of SP17 and NY-ESO-1 and overexpression of p53, WT1, and survivin together with $\beta_{2}$-microglobulin and the $\alpha$-chains, HLA-A and HLA-B/C, in tumor samples obtained from a large well-documented cohort of primary EOC patients using tissue microarray.

\section{Materials and Methods}

2.1. Patients. Since 1985, the Department of Gynecological Oncology of the University Medical Centre Groningen (UMCG) prospectively stores all clinicopathologic and followup data of epithelial ovarian cancer patients in a computerized database. Tumor samples from 361 patients were collected on a tissue microarray. This tissue microarray contains primary ovarian tumor tissue obtained before chemotherapy of 270 patients. Patients with borderline or nonepithelial tumors were excluded. Primary treatment for all patients consisted of surgery and adjuvant chemotherapeutic treatment consistent of platinum-based regimens and others. Since 1995, platinum-based chemotherapy was supplemented by taxanes.

In the current study, the 270 EOC patients were selected for tumor antigen analysis who underwent primary surgery between 1985 and 2006 and of whom sufficient paraffinembedded ovarian tumor tissue and complete followup data were available. In a nonselected subgroup of 183 primary EOC patients, MHC class I expression was analyzed. These data are partly previously published by our group [29].

Patients were surgically staged according to FIGO (International Federation of Gynecology and Obstetrics) classification [31]. Optimal and suboptimal debulking was defined as the largest residual tumor lesions having a diameter of, respectively, $<2 \mathrm{~cm}$ or $\geq 2 \mathrm{~cm}$. Histology of all tumors was determined according to World Health Organization criteria [32].

All relevant data were filed in a separate anonymous database in which patients were given unique codes to protect patient identity. Database management was restricted to two people with access to the larger database containing all patients' characteristics. Due to these procedures, no additional patient or institutional review board approval was required according to Dutch Law.

2.2. Tissue Microarrays. Tissue microarrays were constructed as described previously [17]. Four cores of $0.6 \mathrm{~mm}^{2}$ were taken by biopsy and placed by a tissue microarrayer (Beecher Instruments, Silver Spring, MD, USA) on a recipient paraffin block. Using a microtome, $4 \mu \mathrm{m}$ sections were cut from each tissue microarray block and applied to aminopropyltriethoxysilane-coated slides. All arrayed samples were H\&E-stained to confirm the presence of tumor tissue.

2.3. Immunohistochemical Staining of Tissue Microarrays. Tissue microarray sections were deparaffinized in xylene and rehydrated through graded concentrations of ethanol to distilled water. The sections were boiled for 15 minutes in a microwave to accomplish antigen retrieval. Endogenous peroxidase was blocked by incubation of sections for 30 minutes in $0.3 \%$ hydrogen peroxide. Primary antibodies, antigen retrieval buffers, and detection methods used are provided as supplementary data (Table 1). Sections were counterstained with hematoxylin. All control experiments gave satisfactory results.

2.4. Scoring. Evaluation of immunostaining was independently performed by two observers blinded to the clinical data. Agreement between the two observers was $>90 \%$. Contradictory outcomes were reviewed by a gynecological pathologist and were reassigned by approval of all parties.

Immunostaining for p53, HLA-A, HLA-B/C, and $\beta_{2}-\mathrm{m}$ was scored as described in previous studies $[17,29,30]$. The immunohistochemical reaction for SP17 [33], WT1 $[34,35]$, survivin $[24,36,37]$, and NY-ESO-1 [38] was semiquantitatively graded into four classes based on the frequency of nuclear staining for SP17, WT1, and survivin, and cytoplasmatic staining in NY-ESO-1 in ovarian cancer cells: negative $=$ no/very low frequency $(<5 \%)$ immunopositive cells; $+=$ low frequency $(\leq 5-25 \%) ;++=$ moderate frequency $(25 \%-50 \%) ;+++=$ high frequency $(50 \%-75 \%)$; $++++=$ very high frequency $(75-100 \%)$. The cutoff was 'a priori' chosen for scoring; cases with low frequency or higher were considered positive for tumor antigen expression.

2.5. Statistical Analysis of Data. Statistical analysis was carried out using the SPSS 16.0 software package fow Windows (SPSS Inc., Chicago, USA). All cases with $<2$ evaluable cores were excluded from analysis. 
TABLE 1: Antibodies used for immunohistochemical staining.

\begin{tabular}{lcccc}
\hline Antigen & Antigen retrieval & Clone & Dilution & Company \\
\hline p53 & Tris/EDTA $(\mathrm{pH} 8)$ & DO-7 & $1: 2000$ & DAKO $^{2}$ \\
SP17 & Citrate $(\mathrm{pH} 6)$ & Sp17MF1 & $1: 100$ & 3 \\
survivin & Citrate $(\mathrm{pH} \mathrm{6)}$ & $71 \mathrm{G} 4 \mathrm{~B} 7 \mathrm{E}$ & $1: 100$ & Cell signaling $^{4}$ \\
WT1 & Tris/HCL $(\mathrm{pH} 9)$ & $6 \mathrm{~F}-\mathrm{H} 2$ & $1: 25$ & DAKO $^{2}$ \\
NY-ESO-1 & EDTA $(\mathrm{pH} 8)$ & E978 & $1: 50$ & Zymed \\
HLA-A & Citrate $(\mathrm{pH} 6)$ & HCA2 & $1: 500$ & 6 \\
HLA-B/C & Citrate $(\mathrm{pH} 6)$ & HC-10 & $1: 100$ & 6 \\
$\beta_{2}-\mathrm{m}$ & Citrate $(\mathrm{pH} 6)$ & Polyclonal & $1: 400$ & DAKO $^{2}$ \\
\hline
\end{tabular}

${ }^{1}$ Detects both wild-type and mutant p53 protein; ${ }^{2}$ DAKO, Glostrup, Denmark; ${ }^{3}$ The SP17 antibody kindly provided by Dr. Maurizio Chiriva, Texas Tech University; ${ }^{4}$ Cell Signaling, Danvers, USA $;{ }^{5}$ Zymed, San Francisco, USA; ${ }^{6}$ The HCA2 and HC-10 antibodies were a gift from Professor Dr. Neefjes, Netherlands Cancer Institute, Amsterdam, The Netherlands.

TABle 2: Patient and tumor characteristics.

\begin{tabular}{|c|c|}
\hline & All patients $(n=270)$ \\
\hline \multicolumn{2}{|l|}{ Age (years) } \\
\hline \multirow[t]{2}{*}{ Mean (SD) } & $56.9(13.8)$ \\
\hline & $n(\%)$ \\
\hline \multicolumn{2}{|l|}{ FIGO* stage } \\
\hline Stage I & $67(24.9)$ \\
\hline Stage II & $26(9.7)$ \\
\hline Stage III & $144(53.5)$ \\
\hline Stage IV & $32(11.9)$ \\
\hline Missing & 1 \\
\hline \multicolumn{2}{|l|}{ Tumor type } \\
\hline Serous & $147(59.8)$ \\
\hline Mucinous & $37(15.0)$ \\
\hline Endometrioid & $42(17.1)$ \\
\hline Clear cell & $17(6.9)$ \\
\hline Undifferentiated & $3(1.2)$ \\
\hline Missing & 24 \\
\hline \multicolumn{2}{|c|}{ Differentiation grade } \\
\hline Grade I & $51(20.2)$ \\
\hline Grade II & $77(30.6)$ \\
\hline Grade III & $113(44.8)$ \\
\hline Undifferentiated & $11(4.4)$ \\
\hline Missing & 18 \\
\hline \multicolumn{2}{|l|}{ Residual disease } \\
\hline$<2 \mathrm{~cm}$ & $155(59.0)$ \\
\hline$\geq 2 \mathrm{~cm}$ & $94(35.7)$ \\
\hline Positive** & $21(5.3)$ \\
\hline
\end{tabular}

*FIGO: International Federation of Gynecology and Obstetrics. ** Amount unknown.

\section{Results}

3.1. Patients. Tumor samples from 270 consecutive primary ovarian cancer patients (median age 56.9 years, range 1689) treated at the UMCG between 1985 and 2006 were available (Table 2). The majority of patients presented with serous histology, advanced stage, and/or high-grade disease.
First-line chemotherapy regimens were platinum based in $90(34.2 \%)$ patients and platinum and taxane based in $108(41.1 \%)$ patients. Other regimens were given to 25 (9.5\%) patients, while $40(15.2 \%)$ patients did not receive chemotherapy because of early stage disease, comorbidity, or treatment refusal.

3.2. Tumor Antigen (Over)Expression in EOC. P53, SP17, survivin, WT1, and NY-ESO-1 (over)expression was observed in $48.0 \%, 68.9 \%, 90.0 \%, 56.3 \%$, and $11.0 \%$ of tumors, respectively (Table 3 ). In $93.2 \%$ tumors, at least one of the investigated tumor antigens was (over)expressed (Table 4). Expression of only one tumor antigen was found in 40 (15.2\%) tumors, $70(26.6 \%)$ tumors expressed two antigens, $70(26.6 \%)$ tumors expressed three antigens, $58(22.1 \%)$ tumors expressed four antigens, and 7 (2.7\%) tumors expressed all five investigated tumor antigens. Absence of expression of any antigen was seen in $18(6.8 \%)$ patients. Nonevaluable primary tumors due to core loss during staining procedures or absence of tumor tissue ranged from $19(7.4 \%)$ for SP17 staining to 41 (15.2\%) for WT1 staining. Several specific combinations of tumor antigen expression cover high percentages of EOC patients, varying from $95.5 \%$ (214/224) combining two antigens to a maximum coverage of 98.2\% (216/220) combining four antigens (Table 5).

3.3. Immunostaining MHC Class I. Coexpression of HLA-A and $\beta_{2}-\mathrm{m}$ or HLA-B/C and $\beta_{2}-\mathrm{m}$ was observed in $98(53.6 \%)$ and $136(74.7 \%)$ of the tumors, respectively (Table 3 ). Positive MHC class I expression, defined as HLA-A and $\beta_{2}-$ $\mathrm{m}$ and/or HLA-B/C and $\beta_{2}-\mathrm{m}$ coexpression, was observed in $143(78.1 \%)$ tumors.

3.4. Coexpression of Tumorantigens and MHC Class I in EOC. Of all EOC positive for p53, SP17, survivin, WT1, or NYESO-1, 82.5\%, 82.8\%, 77.0\%, 80.9\%, and 80.0\% were also positive for MHC class I, respectively (Table 6). In $78.4 \%$ of tumors (over)expressing one or more tumor antigens, also expression of MHC class I was found. Furthermore, $74.3 \%$ of all tumors coexpressed MHC class I and at least one tumor antigen. 
TABLE 3: Expression levels of antigen and MHC class I components.

\begin{tabular}{|c|c|c|c|c|c|}
\hline & $\begin{array}{c}\mathrm{P} 53^{1} \\
n(\%)\end{array}$ & $\begin{array}{l}\mathrm{SP}^{1} 7^{1} \\
n(\%)\end{array}$ & $\begin{array}{c}\text { Survivin }^{1} \\
n(\%)\end{array}$ & $\begin{array}{l}\text { WT1 }{ }^{1} \\
n(\%)\end{array}$ & $\begin{array}{c}\text { NY-ESO- } 1^{1} \\
n(\%)\end{array}$ \\
\hline Normal/negative & $130(52.0)$ & $78(31.1)$ & $23(10.0)$ & $100(43.7)$ & $219(89.0)$ \\
\hline Overexpression/positive & $120(48.0)$ & $173(68.9)$ & $208(90.0)$ & $129(56.3)$ & $27(11.0)$ \\
\hline \multirow[t]{2}{*}{ Missing } & 20 & 19 & 39 & 41 & 24 \\
\hline & HLA $-\mathrm{A}^{+} / \beta_{2}-\mathrm{m}^{+2}$ & HLA-B $/ \mathrm{C}^{+} / \beta_{2}-\mathrm{m}^{+2}$ & MHC class $\mathrm{I}^{3}$ & & \\
\hline Positive $^{4}$ & $98(53.6)$ & $136(74.7)$ & $143(78.1)$ & & \\
\hline Negative $^{4}$ & $85(46.4)$ & $46(25.3)$ & $40(21.9)$ & & \\
\hline Missing & & 1 & & & \\
\hline
\end{tabular}

TABLE 4: Expression of single or multiple antigens in EOC.

\begin{tabular}{lccc}
\hline Number of antigens & $n$ & $\%$ & Cumulative \% \\
\hline 1 & 40 & 15.2 & 15.2 \\
2 & 70 & 26.6 & 41.8 \\
3 & 70 & 26.6 & 68.4 \\
4 & 58 & 22.1 & 90.5 \\
5 & 7 & 2.7 & 93.2 \\
None & 18 & 6.8 & 100.0 \\
Missing & 7 & & \\
\hline
\end{tabular}

$n=270$.

\section{Discussion}

In a large well-documented cohort of representative EOC patients, (over)expression of at least one of the tumor antigens p53, SP17, survivin, WT1, or NY-ESO-1 was observed in over $90 \%$ of the tumors. To our knowledge, this is the first study on the expression of multiple tumor antigens in a large cohort of EOC. Only a minority $(6.8 \%)$ of the tumors did not express one of the selected tumor antigens. About $75 \%$ of the EOC tumors expressed both, one of the tumor antigens and MHC class I. This observation underlines the relevance of designing a multiepitope vaccine consisting of p53, SP17, NY-ESO-1, survivin, and WT1 for the immunotherapeutic treatment of ovarian cancer.

This inventory tissue microarray study enables us to analyze the expression of five well-known tumor antigens in EOC, in correlation to MHC class I expression. Tissue microarray is a practical and powerful tool for highthroughput analysis of tumor tissue identifying targets in human cancers [39]. P53, SP17, NY-ESO-1, survivin, and WT1 are immunogenic target antigens in EOC. Rates of observed (over)expression of p53, SP17, survivin, and WT1 in $48.0 \%, 68.9 \%, 90.0 \%$, and $56.3 \%$ of EOC patients, respectively, are in agreement with previous studies $[16,24$, 40,41 ]. NY-ESO-1 expression was seen in $11.0 \%$ of tumors in our cohort which is in agreement with the results of others [42, 43]. However, Odunsi et al. observed NY-ESO-1 expression in $43 \%$ of EOC patients $[38,44]$. This difference in expression might be explained by considerable methodological variability among the different studies. The type of study design, antibodies and assays used to study NY-ESO-1 expression, determination of cutoff points for aberrant NYESO-1 expression, and the definition of study end points vary greatly among different studies. Immunohistochemical analyses of tumors have shown heterogeneous NY-ESO-1 expression [45]. Since expression of NY-ESO-1 is mostly focal and nonuniform, tissue microarrays containing large numbers of tumor tissue are essential to determine NY-ESO1 expression in EOC. Our sample size of 270 EOC patients might be more potent to distinguish between positive and negative NY-ESO-1 expression in EOC compared to 143 EOC patients analyzed by Odunsi et al.

We previously reported on the expression of tumor antigens EGFR and Her-2 in our large well-documented cohort of representative EOC, using tissue microarray [46]. EGFR and Her-2 overexpression was observed in $7.0 \%$ and $5.2 \%$ of EOC, respectively. The expression of EGFR and Her-2 has been extensively studied in ovarian cancer $[47,48]$. Aberrant activity of these antigens is important in tumor growth and development [49, 50]. Therefore, EGFR and Her-2 were considered to be attractive targets for immunotherapeutic strategies in EOC. Because of the low expression levels in EOC, therapeutic potential of vaccines targeting EGFR and Her-2 is limited. As the existing repertoire of known antigens in EOC is relatively small, we performed our innovative study on five highly expressed tumor antigens which may provide opportunities for multiepitope immunotherapeutic strategies targeting the majority of EOC patients.

We provide first evidence that several antigen combinations can be used in a multiepitope vaccine for EOC treatment, since different antigen combinations cover high percentages of EOC patients. Vaccines comprising a mixture of, for example, p53, SP17, and survivin or combining survivin, WT1, and NY-ESO-1 cover the vast majority of EOC patients. Maximum coverage of EOC patients can be obtained by a vaccine comprising four antigens p53, SP17, survivin, and WT1.

Single antigen vaccines targeting p53 [51], SP17 [40], NY-ESO-1 [52], survivin [11], and WT1 [22] have been described to generate tumor antigen-specific cytotoxic T-cell lymphocytes (CTLs) able to lyse autologous tumor 
TABLE 5: Expression of specific antigen combinations in EOC.

\begin{tabular}{|c|c|}
\hline Antigen combinations & $\%(n /$ total $)$ \\
\hline \multicolumn{2}{|l|}{ One antigen } \\
\hline p53 & $48.0(120 / 250)$ \\
\hline SP17 & $68.9(173 / 251)$ \\
\hline Survivin & $90.0(208 / 231)$ \\
\hline WT1 & $56.3(129 / 229)$ \\
\hline NY-ESO-1 & $11.0(27 / 246)$ \\
\hline \multicolumn{2}{|l|}{ Two antigens } \\
\hline p53, SP17 & $84.2(203 / 241)$ \\
\hline p53, survivin & $95.5(214 / 224)$ \\
\hline p53, WT1 & $73.1(163 / 223)$ \\
\hline p53, NY-ESO-1 & $52.7(125 / 237)$ \\
\hline SP17, surviving & $94.7(215 / 227)$ \\
\hline SP17, WT1 & $82.3(186 / 226)$ \\
\hline SP17, NY-ESO-1 & $74.0(179 / 242)$ \\
\hline survivin, WT1 & $93.0(212 / 228)$ \\
\hline survivin, NY-ESO-1 & $90.8(208 / 229)$ \\
\hline WT1, NY-ESO-1 & $60.3(138 / 229)$ \\
\hline \multicolumn{2}{|l|}{ Three antigens } \\
\hline p53, SP17, survivin & $97.7(217 / 222)$ \\
\hline p53, SP17, WT1 & $91.4(202 / 221)$ \\
\hline p53, SP17, NY-ESO-1 & $86.4(203 / 235)$ \\
\hline p53, survivin, WT1 & $95.9(213 / 222)$ \\
\hline p53, survivin, NY-ESO-1 & $95.5(213 / 223)$ \\
\hline p53, WT1, NY-ESO-1 & $74.4(166 / 223)$ \\
\hline SP17, survivin, WT1 & $96.0(216 / 225)$ \\
\hline SP17, survivin, NY-ESO-1 & $95.6(216 / 226)$ \\
\hline SP17, WT1, NY-ESO-1 & $84.5(191 / 226)$ \\
\hline survivin, WT1, NY-ESO-1 & $93.4(213 / 228)$ \\
\hline \multicolumn{2}{|l|}{ Four antigens } \\
\hline p53, SP17, survivin, WT1 & $98.2(216 / 220)$ \\
\hline p53, SP17, survivin, NY-ESO-1 & $97.7(216 / 221)$ \\
\hline p53, SP17, WT1, NY-ESO-1 & $92.3(204 / 221)$ \\
\hline p53, survivin, WT1, NY-ESO-1 & $95.9(213 / 222)$ \\
\hline SP17, survivin, WT1, NY-ESO-1 & $96.4(217 / 225)$ \\
\hline \multicolumn{2}{|l|}{ All antigens } \\
\hline p53, SP17, survivin, WT1, NY-ESO-1 & $98.2(216 / 220)$ \\
\hline
\end{tabular}

cells. One can envision that multiepitope vaccines may enhance immunogenicity, improving clinical efficacy of the immunotherapeutic vaccine.

Multiepitope vaccines should preferably contain multiple MHC class I-presented CTL epitopes derived from different target antigens together with a tumor-specific MHC class II-presented T-helper epitope. This will reduce the risk of immune-driven selection of antigen-loss variants of the tumor. Next, given the pivotal role of T-helper cells in promoting the primary and secondary CTL responses through the induction of DC maturation and the production of cytokines, the inclusion of T-helper epitopes in a multiepitope-based vaccine will have strong beneficial effects
[6]. For example, p53-specific T-helper cells induced upon p53 specific immunization might fulfil this role [53].

Important advantages of well-defined multiepitope vaccines over nondefined vaccines, such as tumor lysate vaccines, are their defined nature $[6,54]$, lack of suppressive inducing antigens [55-57], simple way of manipulation to prevent dominance of one antigen over the others $[6$, 58], universal applicability $[6,59]$, easiness to make in a standardized procedure $[59,60]$, possibility to combine with other strategies [59], and limited autoimmune toxicity [55, 61].

Moreover, administration of a multiepitope vaccine as a single mixture offers advantages including: (1) injection of a limited volume, (2) lower number of skin sites with local toxicity due to injection site reactions, and (3) lower chance of error and contamination with the preparation of one versus multiple epitope preparations $[13,14]$.

In contrast, previous studies showed that administration of multiple epitopes at one injection site could lead to a more vigorous response to just one of the involved antigens $[62,63]$. We reasoned that this disadvantageous result might be due to immunodominance of one antigen over the other. Preclinical studies might be helpful in designing the optimal combination of multiantigen vaccines, trying to predict and/or prevent immunodominance. In contrast, the synergy between antigens included in a multiepitope vaccine might induce immune responses with increased potency compared with the response induced by the same epitopes individually [6]. Separate injection sites for all of the involved antigens may result in a significant increase in the magnitude of the antigen-specific T-cell response. It still holds true that several multiantigen combinations cover high percentages of tumors. The most favourable vaccine, based on (pre)clinical studies concerning immunodominance, can be used for treatment of EOC patients.

MHC class I downregulation was observed in $21.9 \%$ of tumors. Loss of MHC class I molecules on tumor cells, which may lead to immune escape, is often restricted to one or a few alleles. Targeting multiple epitopes restricted by different class I molecules of the patient will likely circumvent such an escape mechanism [6]. The tumorassociated antigens p53, NY-ESO-1, and WT1 epitopes are presented both by MHC class I and II (according to listing at http://www.cancerimmunity.org/, update September 2008). As a result, p53, WT1, and NY-ESO-1 [64] can function as both CTL and T-helper cell targets.

Considering the importance of the expression of $\mathrm{MHC}$ class I by tumor cells for immune recognition by $\mathrm{T}$ cells, several regimens could be added in the multiepitope vaccine to enhance MHC class I expression. Treatment with IFNgamma is known to upregulate MHC class I $[10,65,66]$. Another possibility would be the addition of demethylating agents to the multiepitope vaccine, since DNA hypermethylation, common in human tumors, may result in the loss of MHC class I expression $[67,68]$.

The most promising finding that emerges from this study is that the vast majority of EOC patients present one or more tumor antigens. Furthermore, if tumor cells present one of our investigated tumor antigens, it is likely to express 
TABLE 6: Coexpression of MHC class I components with tumorantigens.

\begin{tabular}{|c|c|c|c|c|c|c|}
\hline & $\begin{array}{c}{\mathrm{p} 53^{+}} \\
n=80 \\
n / \text { total }(\%)\end{array}$ & $\begin{array}{c}\mathrm{SP} 17^{+} \\
n=116 \\
n / \text { total }(\%)\end{array}$ & $\begin{array}{c}\text { Survivin }^{+} \\
n=152 \\
n / \text { total }(\%)\end{array}$ & $\begin{array}{c}\mathrm{WT}^{+} \\
n=89 \\
n / \text { total }(\%)\end{array}$ & $\begin{array}{c}\text { NY-ESO }^{+} \\
n=20 \\
n / \text { total }(\%)\end{array}$ & $\begin{array}{c}\text { Tumorantigen }^{+2} \\
n=173 \\
n / \text { total }(\%)\end{array}$ \\
\hline$H L A-A^{+} \beta_{2} m^{+}$ & $52 / 80$ & $64 / 116$ & $80 / 152$ & $50 / 89$ & $13 / 20$ & $96 / 173$ \\
\hline$n=98$ & $(65.0)$ & $(55.2)$ & $(52.6)$ & $(56.2)$ & $(65.0)$ & $(55.0)$ \\
\hline$H L A-B / C^{+} \beta_{2} m^{+}$ & $62 / 78$ & $94 / 116$ & $111 / 151$ & $67 / 89$ & $15 / 20$ & $129 / 171$ \\
\hline$n=136$ & $(79.5)$ & $(81.0)$ & $(73.5)$ & $(75.3)$ & $(75.0)$ & $(75.4)$ \\
\hline MHC class $I^{+}$ & $66 / 80$ & $96 / 116$ & $117 / 152$ & $72 / 89$ & $16 / 20$ & $136 / 173$ \\
\hline$n=143$ & $(82.5)$ & $(82.8)$ & $(77.0)$ & $(80.9)$ & $(80.0)$ & $(78.4)$ \\
\hline All patients ${ }^{1}$ & $66 / 174$ & $96 / 178$ & $117 / 169$ & $72 / 167$ & $16 / 175$ & $136 / 183$ \\
\hline$n=183$ & $(37.9)$ & $(53.9)$ & $(69.2)$ & $(43.1)$ & $(9.1)$ & $(74.3)$ \\
\hline
\end{tabular}

${ }^{1}$ Antigen $^{+}$and MHC class I ${ }^{+}$in all subgroup patients $(n=183) ;{ }^{2} \geq 1$ tumorantigen expression.

MHC class I as well. Therefore, a vaccine comprising the investigated tumor antigens is capable of targeting tumor cells of the vast majority of EOC patients. Since several combinations of tumor antigens cover the majority of EOC patients, different institutes can attribute personally preferred antigens to their multiepitope vaccine.

In summary, we are first to show that multiepitope immunotherapy combining tumor antigens p53, SP17, survivin, WT1, and/or NY-ESO-1 might be a promising new therapeutic vaccination strategy in ovarian cancer.

\section{Conflict of Interest Statement}

The authors declare that there are no conflicts of interest.

\section{References}

[1] A. Jemal, R. Siegel, J. Xu, and E. Ward, "Cancer statistics, 2010," Ca: A Cancer Journal for Clinicians. In press.

[2] C. H. Holschneider and J. S. Berek, "Ovarian cancer: epidemiology, biology, and prognostic factors," Seminars in Surgical Oncology, vol. 19, no. 1, pp. 3-10, 2000.

[3] M. A. Bookman, "Standard treatment in advanced ovarian cancer in 2005: the state of the art," International Journal of Gynecological Cancer, vol. 15, no. 6, pp. 212-220, 2005.

[4] F. Coilinson and G. Jayson, "New therapeutic agents in ovarian cancer," Current Opinion in Obstetrics and Gynecology, vol. 21, no. 1, pp. 44-53, 2009.

[5] H. T. Khong and N. P. Restifo, "Natural selection of tumor variants in the generation of "tumor escape" phenotypes," Nature Immunology, vol. 3, no. 11, pp. 999-1005, 2002.

[6] J. H. Kessler and C. J. M. Melief, "Identification of T-cell epitopes for cancer immunotherapy," Leukemia, vol. 21, no. 9, pp. 1859-1874, 2007.

[7] I. M. Svane, A. E. Pedersen, K. Nikolajsen, and M.-B. Zocca, "Alterations in p53-specific $\mathrm{T}$ cells and other lymphocyte subsets in breast cancer patients during vaccination with p53peptide loaded dendritic cells and low-dose interleukin-2," Vaccine, vol. 26, no. 36, pp. 4716-4724, 2008.

[8] J. Kuball, M. Schuler, E. Antunes Ferreira et al., "Generating p53-specific cytotoxic T lymphocytes by recombinant adenoviral vector-based vaccination in mice, but not man," Gene Therapy, vol. 9, no. 13, pp. 833-843, 2002.
[9] A. G. Menon, P. J. K. Kuppen, S. H. van der Burg et al., "Safety of intravenous administration of a canarypox virus encoding the human wild-type p53 gene in colorectal cancer patients," Cancer Gene Therapy, vol. 10, no. 7, pp. 509-517, 2003.

[10] C. Chaise, S. L. Buchan, J. Rice et al., "DNA vaccination induces WT1-specific T-cell responses with potential clinical relevance," Blood, vol. 112, no. 7, pp. 2956-2964, 2008.

[11] T. Tsuruma, Y. Iwayama, T. Ohmura et al., "Clinical and immunological evaluation of anti-apoptosis protein, survivinderived peptide vaccine in phase I clinical study for patients with advanced or recurrent breast cancer," Journal of Translational Medicine, vol. 6, article 24, 2008.

[12] C. S. M. Diefenbach, S. Gnjatic, P. Sabbatini et al., "Safety and immunogenicity study of NY-ESO-1b peptide and montanide ISA-51 vaccination of patients with epithelial ovarian cancer in high-risk first remission," Clinical Cancer Research, vol. 14, no. 9, pp. 2740-2748, 2008.

[13] K.A. Chianese-Bullock, S. T. Lewis, N. E. Sherman, J. D. Shannon, and C. L. Slingluff Jr., "Multi-peptide vaccines vialed as peptide mixtures can be stable reagents for use in peptidebased immune therapies," Vaccine, vol. 27, no. 11, pp. 17641770, 2009.

[14] J. M. Straughn Jr., D. R. Shaw, A. Guerrero et al., "Expression of sperm protein 17 (Sp17) in ovarian cancer," International Journal of Cancer, vol. 108, no. 6, pp. 805-811, 2004.

[15] J. M. Kirkwood, S. Lee, S. Moschos et al., "Immunogenicity and antitumor effects of vaccination with peptide vaccine $+/$ - granulocyte-monocyte colony-stimulating factor and/or IFIN- $\alpha 2 b$ in advanced metastatic melanoma: eastern cooperative oncology group phase II trial E1696," Clinical Cancer Research, vol. 15, no. 4, pp. 1443-1451, 2009.

[16] H. W. Nijman, A. Lambeck, S. H. van der Burg, A. G. J. van der Zee, and T. Daemen, "Immunologic aspect of ovarian cancer and p53 as tumor antigen," Journal of Translational Medicine, vol. 3, article 34, 2005.

[17] P. de Graeff, J. Hall, A. P. G. Crijns et al., "Factors influencing p53 expression in ovarian cancer as a biomarker of clinical outcome in multicentre studies," British Journal of Cancer, vol. 95, no. 5, pp. 627-633, 2006.

[18] A. Lambeck, N. Leffers, B.-N. Hoogeboom et al., "P53specific $\mathrm{T}$ cell responses in patients with malignant and benign ovarian tumors: implications for p53 based immunotherapy," International Journal of Cancer, vol. 121, no. 3, pp. 606-614, 2007.

[19] M. Chiriva-Internati, F. Grizzi, J. A.Weidanz et al., "A NOD/SCID tumor model for human ovarian cancer that 
allows tracking of tumor progression through the biomarker Sp17," Journal of Immunological Methods, vol. 321, no. 1-2, pp. 86-93, 2007.

[20] T. Nakazato, T. Kanuma, T. Tamura, L. S. Faried, H. Aoki, and T. Minegishi, "Sperm protein 17 influences the tissue-specific malignancy of clear cell adenocarcinoma in human epithelial ovarian cancer," International Journal of Gynecological Cancer, vol. 17, no. 2, pp. 426-432, 2007.

[21] Y. Oka, A. Tsuboi, Y. Oji, I. Kawase, and H. Sugiyama, "WT1 peptide vaccine for the treatment of cancer," Current Opinion in Immunology, vol. 20, no. 2, pp. 211-220, 2008.

[22] G. Li, Y. Zeng, X. Chen et al., "Human ovarian tumour-derived chaperone-rich cell lysate (CRCL) elicits $\mathrm{T}$ cell responses in vitro," Clinical and Experimental Immunology, vol. 148, no. 1, pp. 136-145, 2007.

[23] H. J. Stauss, S. Thomas, M. Cesco-Gaspere et al., "WT1specific T cell receptor gene therapy: improving TCR function in transduced T cells," Blood Cells, Molecules, and Diseases, vol. 40, no. 1, pp. 113-116, 2008.

[24] C. Cohen, C. M. Lohmann, G. Cotsonis, D. Lawson, and R. Santoianni, "Survivin expression in ovarian carcinoma: correlation with apoptotic markers and prognosis," Modern Pathology, vol. 16, no. 6, pp. 574-583, 2003.

[25] L. Sui, Y. Dong, M. Ohno, Y. Watanabe, K. Sugimoto, and M. Tokuda, "Survivin expression and its correlation with cell proliferation and prognosis in epithelial ovarian tumors," International Journal of Oncology, vol. 21, no. 2, pp. 315-320, 2002.

[26] N. Zaffaroni, M. Pennati, G. Colella et al., "Expression of the anti-apoptotic gene survivin correlates with taxol resistance in human ovarian cancer," Cellular and Molecular Life Sciences, vol. 59, no. 8, pp. 1406-1412, 2002.

[27] J. Matsuzaki, F. Qian, I. Luescher et al., "Recognition of naturally processed and ovarian cancer reactive $\mathrm{CD} 8^{+} \mathrm{T}$ cell epitopes within a promiscuous HLA class II T-helper region of NY-ESO-1," Cancer Immunology, Immunotherapy, vol. 57, no. 8, pp. 1185-1195, 2008.

[28] Y.-T. Chen, M. Hsu, P. Lee et al., "Cancer/testis antigen CT45: analysis of mRNA and protein expression in human cancer," International Journal of Cancer, vol. 124, no. 12, pp. 2893 2898, 2009.

[29] N. Leffers, M. J. M. Gooden, A. A. Mokhova et al., "Downregulation of proteasomal subunit MB1 is an independent predictor of improved survival in ovarian cancer," Gynecologic Oncology, vol. 113, no. 2, pp. 256-263, 2009.

[30] N. Leffers, A. J. A. Lambeck, P. de Graeff et al., "Survival of ovarian cancer patients overexpressing the tumour antigen p53 is diminished in case of MHC class I down-regulation," Gynecologic Oncology, vol. 110, no. 3, pp. 365-373, 2008.

[31] "Cancer Committee of the International Federation of Gynaecology and Obstetrics. Staging announcement: FIGO Cancer Committee," Gynecological Oncology, vol. 25, pp. 383-385, 1986.

[32] R. E. Scully, "Histological typing of ovarian tumours," in World Health Organisation. International Histological Classification of Tumours, pp. 11-19, Springer, Berlin, Germany, 2004.

[33] F. Grizzi, P. Gaetani, B. Franceschini et al., "Sperm protein 17 is expressed in human nervous system tumours," BMC Cancer, vol. 6, article 23, 2006.

[34] G. Acs, T. Pasha, and P. J. Zhang, "WT1 is differentially expressed in serous, endometrioid, clear cell, and mucinous carcinomas of the peritoneum, fallopian tube, ovary, and endometrium," International Journal of Gynecological Pathology, vol. 23, no. 2, pp. 110-118, 2004.
[35] M. Shimizu, T. Toki, Y. Takagi, I. Konishi, and S. Fujii, "Immunohistochemical detection of the Wilms' tumor gene (WT1) in epithelial ovarian tumors," International Journal of Gynecological Pathology, vol. 19, no. 2, pp. 158-163, 2000.

[36] L. Kleinberg, V. A. Florenes, I. Silins et al., "Nuclear expression of survivin is associated with improved survival in metastatic ovarian carcinoma," Cancer, vol. 109, no. 2, pp. 228-238, 2007.

[37] G. Ferrandina, F. Legge, E. Martinelli et al., "Survivin expression in ovarian cancer and its correlation with clinicopathological, surgical and apoptosis-related parameters," British Journal of Cancer, vol. 92, no. 2, pp. 271-277, 2005.

[38] K. Odunsi, A. A. Jungbluth, E. Stockert et al., "NY-ESO-1 and LAGE-1 cancer-testis antigens are potential targets for immunotherapy in epithelial ovarian cancer," Cancer Research, vol. 63, no. 18, pp. 6076-6083, 2003.

[39] N. M. T. Jawhar, "Tissue microarray: a rapidly evolving diagnostic and research tool," Annals of Saudi Medicine, vol. 29, no. 2, pp. 123-127, 2009.

[40] M. Chiriva-Internati, Z. Wang, E. Salati, P. Timmins, and S. H. Lim, "Tumor vaccine for ovarian carcinoma targeting sperm protein 17," Cancer, vol. 94, no. 9, pp. 2447-2453, 2002.

[41] M. V. Barbolina, B. P. Adley, L. D. Shea, and M. S. Stack, "Wilms tumor gene protein 1 is associated with ovarian cancer metastasis and modulates cell invasion," Cancer, vol. 112, no. 7, pp. 1632-1641, 2008.

[42] K. Milne, R. O. Barnes, A. Girardin et al., "Tumor-infiltrating T cells correlate with NY-ESO-1-specific autoantibodies in ovarian cancer," PLoS ONE, vol. 3, no. 10, article e3409, 2008.

[43] E. Yakirevich, E. Sabo, O. Lavie, S. Mazareb, G. C. Spagnoli, and M. B. Resnick, "Expression of the MAGE-A4 and NYESO-1 cancer-testis antigens in serous ovarian neoplasms," Clinical Cancer Research, vol. 9, no. 17, pp. 6453-6460, 2003.

[44] A. Woloszynska-Read, P. Mhawech-Fauceglia, J. Yu, K. Odunsi, and A. R. Karpf, "Intertumor and intratumor NYESO-1 expression heterogeneity Is associated With promoterspecific and global DNA methylation status in ovarian cancer," Clinical Cancer Research, vol. 14, no. 11, pp. 3283-3290, 2008.

[45] M. J. Scanlan, A. O. Gure, A. A. Jungbluth, L. J. Old, and Y.-T. Chen, "Cancer/testis antigens: an expanding family of targets for cancer immunotherapy," Immunological Reviews, vol. 188, pp. 22-32, 2002.

[46] P. de Graeff, A. P. G. Crijns, K. A. ten Hoor et al., "The ErbB signalling pathway: protein expression and prognostic value in epithelial ovarian cancer," British Journal of Cancer, vol. 99, no. 2, pp. 341-349, 2008.

[47] M. V. Seiden, H. A. Burris, U. Matulonis et al., "A phase II trial of EMD72000 (matuzumab), a humanized anti-EGFR monoclonal antibody, in patients with platinum-resistant ovarian and primary peritoneal malignancies," Gynecologic Oncology, vol. 104, no. 3, pp. 727-731, 2007.

[48] C.-H. Lee, D. G. Huntsman, M. C. U. Cheang et al., "Assessment of Her-1, Her-2, and Her-3 expression and Her-2 amplification in advanced stage ovarian carcinoma," International Journal of Gynecological Pathology, vol. 24, no. 2, pp. 147-152, 2005.

[49] D. E. Milenic, K. J. Wong, K. E. Baidoo et al., "Cetuximab: preclinical evaluation of a monoclonal antibody targeting EGFR for radioimmunodiagnostic and radioimmunotherapeutic applications," Cancer Biotherapy and Radiopharmaceuticals, vol. 23, no. 5, pp. 619-631, 2008.

[50] E. Horak, F. Hartmann, K. Garmestani et al., "Radioimmunotherapy targeting of HER2/neu oncoprotein on ovarian tumor using lead-212-DOTA-AE1," Journal of Nuclear Medicine, vol. 38, no. 12, pp. 1944-1950, 1997. 
[51] I. M. Svane, A. E. Pedersen, H. E. Johnsen et al., "Vaccination with p53-peptide-pulsed dendritic cells, of patients with advanced breast cancer: report from a phase I study," Cancer Immunology, Immunotherapy, vol. 53, no. 7, pp. 633-641, 2004.

[52] K. Odunsi, F. Qian, J. Matsuzaki et al., "Vaccination with an NY-ESO-1 peptide of HLA class I/II specificities induces integrated humoral and T cell responses in ovarian cancer," Proceedings of the National Academy of Sciences of the United States of America, vol. 104, no. 31, pp. 12837-12842, 2007.

[53] N. Leffers, A. J. A. Lambeck, M. J. M. Gooden et al., "Immunization with a P53 synthetic long peptide vaccine induces P53-specific immune responses in ovarian cancer patients, a phase II trial," International Journal of Cancer, vol. 125, no. 9, pp. 2104-2113, 2009.

[54] J. Galea-Lauri, J. W. Wells, D. Darling, P. Harrison, and F. Farzaneh, "Strategies for antigen choice and priming of dendritic cells influence the polarization and efficacy of antitumor T-cell responses in dendritic cell-based cancer vaccination," Cancer Immunology, Immunotherapy, vol. 53, no. 11, pp. 963-977, 2004.

[55] R. R. Caspi, "Immunotherapy of autoimmunity and cancer: the penalty for success," Nature Reviews Immunology, vol. 8, no. 12, pp. 970-976, 2008.

[56] J. M. Kirkwood, A. A. Tarhini, M. C. Panelli et al., "Next generation of immunotherapy for melanoma," Journal of Clinical Oncology, vol. 26, no. 20, pp. 3445-3455, 2008.

[57] P. Hwu and R. S. Freedman, "The immunotherapy of patients with ovarian cancer," Journal of Immunotherapy, vol. 25, no. 3, pp. 189-201, 2002.

[58] A. L. Glazyrin, J. Kan-Mitchell, and M. S. Mitchell, "Analysis of in vitro immunization: generation of cytotoxic T-lymphocytes against allogeneic melanoma cells with tumor lysate-loaded or tumor RNA-transfected antigen-presenting cells," Cancer Immunology, Immunotherapy, vol. 52, no. 3, pp. 171-178, 2003.

[59] C.-F. Hung, T. C. Wu, A. Monie, and R. Roden, "Antigenspecific immunotherapy of cervical and ovarian cancer," Immunological Reviews, vol. 222, no. 1, pp. 43-69, 2008.

[60] C. J. Kim, S. Dessureault, D. Gabrilovich, D. S. Reintgen, and C. L. Slingluff Jr., "Immunotherapy for melanoma," Cancer Control, vol. 9, no. 1, pp. 22-30, 2002.

[61] M. J. Cannon, A. D. Santin, and T. J. O’Brien, "Immunological treatment of ovarian cancer," Current Opinion in Obstetrics and Gynecology, vol. 16, no. 1, pp. 87-92, 2004.

[62] G. G. Kenter, M. J. P. Welters, A. R. P. M. Valentijn et al., "Phase I immunotherapeutic trial with long peptides spanning the E6 and E7 sequences of high-risk human papillomavirus 16 in end-stage cervical cancer patients shows low toxicity and robust immunogenicity," Clinical Cancer Research, vol. 14, no. 1, pp. 169-177, 2008.

[63] M. J. Palmowski, E. M.-L. Choi, I. F. Hermans et al., "Competition between CTL narrows the immune response induced by prime-boost vaccination protocols," Journal of Immunology, vol. 168, no. 9, pp. 4391-4398, 2002.

[64] N. N. Hunder, H. Wallen, J. Cao et al., "Treatment of metastatic melanoma with autologous $\mathrm{CD} 4^{+} \mathrm{T}$ cells against NY-ESO-1," The New England Journal of Medicine, vol. 358, no. 25, pp. 2698-2703, 2008.

[65] C. Doehn, N. Esser, H.-G. Pauels et al., "Mode-of-action, efficacy, and safety of a homologous multi-epitope vaccine in a murine model for adjuvant treatment of renal cell carcinoma," European Urology, vol. 56, no. 1, pp. 123-133, 2009.
[66] Y. Nie, G.-Y. Yang, Y. Song et al., "DNA hypermethylation is a mechanism for loss of expression of HLA class I genes in human esophageal squamous cell carcinomas," Carcinogenesis, vol. 22, no. 10, pp. 1615-1623, 2001.

[67] C. Sers, R. Kuner, C. S. Falk et al., "Down-regulation of HLA class I and NKG2D ligands through a concerted action of MAPK and DNA methyltransferases in colorectal cancer cells," International Journal of Cancer, vol. 125, no. 7, pp. 1626-1639, 2009.

[68] A. Serrano, S. Tanzarella, I. Lionello et al., "Expression of HLA class I antigens and restoration of antigen-specific CTL response in melanoma cells following 5-aza-2' -deoxycytidine treatment," International Journal of Cancer, vol. 94, no. 2, pp. 243-251, 2001. 


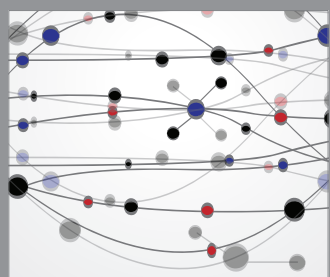

The Scientific World Journal
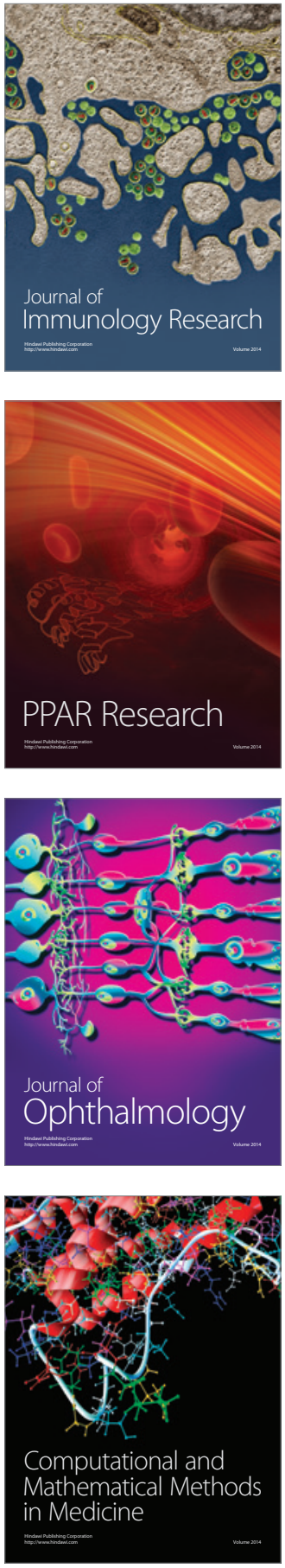

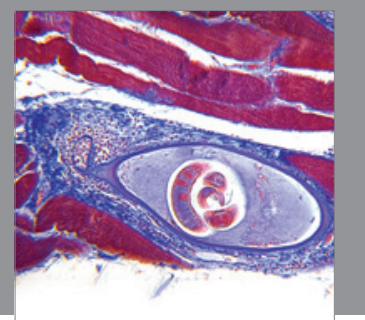

Gastroenterology

Research and Practice
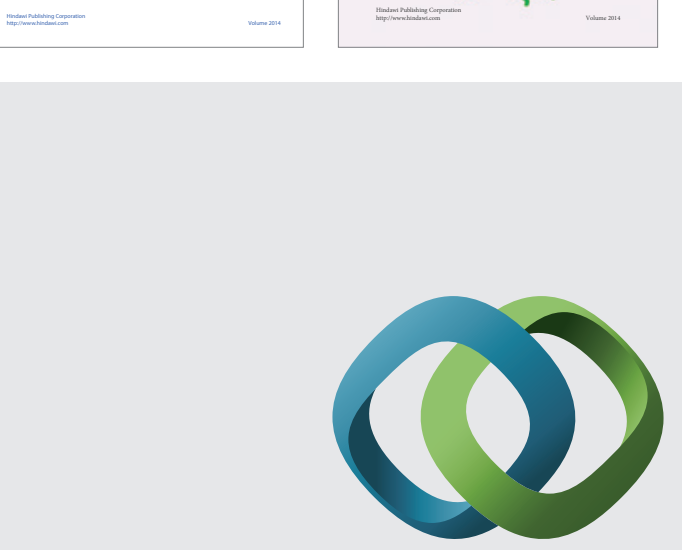

\section{Hindawi}

Submit your manuscripts at

http://www.hindawi.com
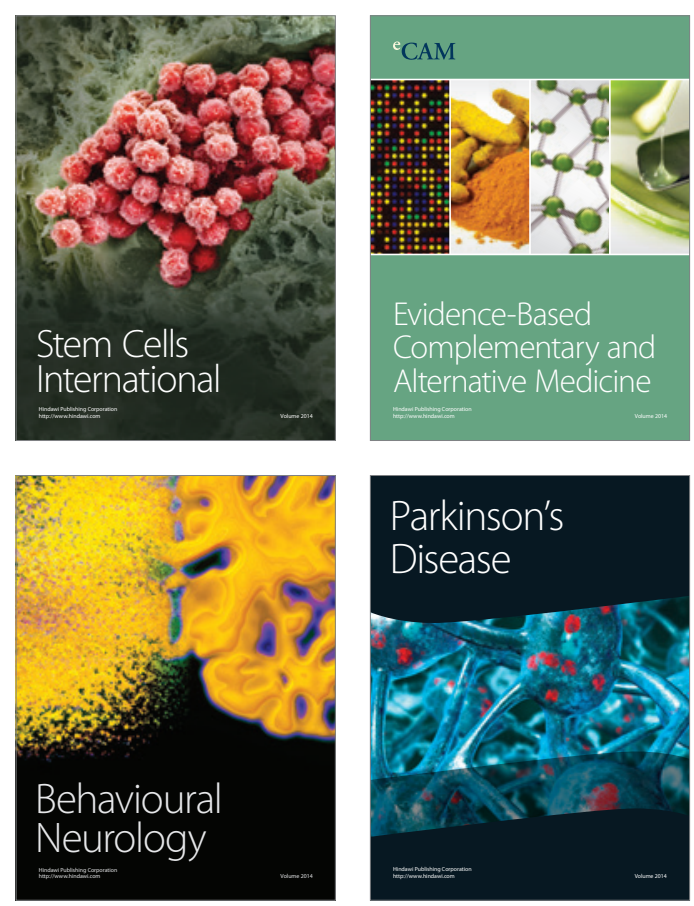

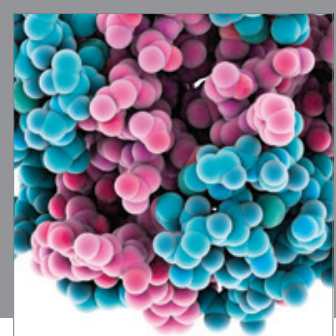

Journal of
Diabetes Research

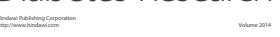

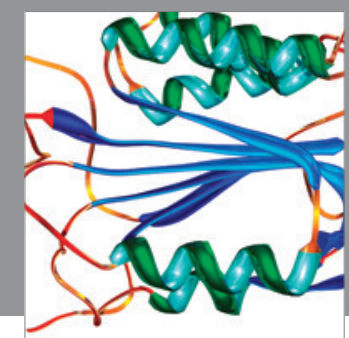

Disease Markers
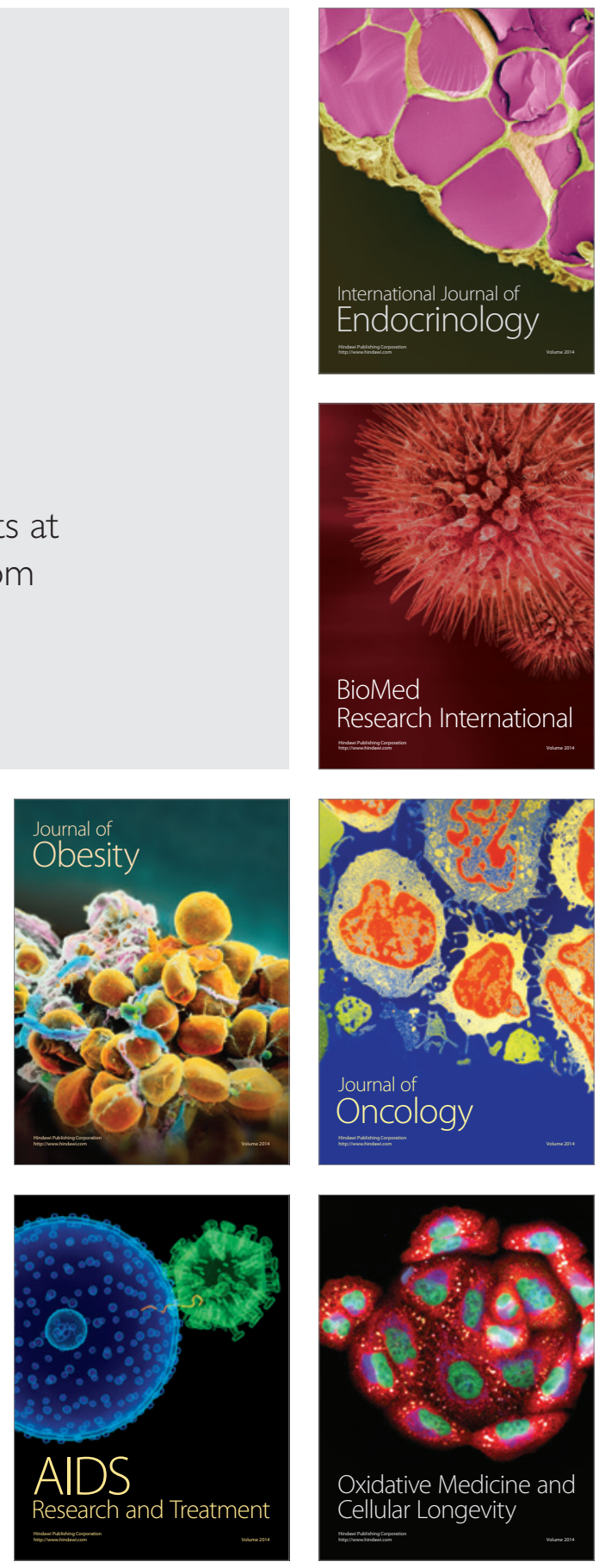